\title{
New and Evolving Immunotherapy in Inflammatory Bowel Disease
}

\author{
Mohamad A. Raad ${ }^{a}$ Nour H. Chams ${ }^{a}$ Ala I. Sharara ${ }^{b}$ \\ ${ }^{a}$ School of Medicine, American University of Beirut, and ${ }^{b}$ Division of Gastroenterology, Department of \\ Internal Medicine, American University of Beirut Medical Center, Beirut, Lebanon
}

\section{Key Words}

Biologics · Crohn's disease - Inflammatory bowel disease .

Treatment · Ulcerative colitis

\begin{abstract}
Background: Crohn's disease and ulcerative colitis are chronic inflammatory disorders associated with a dysregulated adaptive and innate immune response to gut commensals in genetically susceptible individuals. The pathogenesis of inflammatory bowel disease is complex, and the disease is characterized by significant phenotypic and genotypic heterogeneity. Summary: The introduction of anti-TNF biologics has resulted in improved clinical outcomes in patients with severe and moderately severe disease, but the current treatment paradigm continues to depend on systemic immunosuppression (steroids and immunomodulators) and surgical intervention in a significant number of patients, underscoring a significant unmet need. More recently, a number of genetic and immunologic abnormalities have been unraveled including aberrant intestinal mucosal defense function, abnormal intestinal permeability, dysregulated bacterial antigen processing by macrophages and presentation to T cells, cellular immune regulation and signaling, cytokine production, and leukocyte trafficking. Key Messages: Understanding these molecular mechanisms and effector pathways presents an opportunity for the development of new and improved targeted therapies.

(c) 2016 S. Karger AG, Basel
\end{abstract}

(c) 2016 S. Karger AG, Basel

2296-9403/16/0012-0085\$39.50/0

\section{Introduction}

Inflammatory bowel disease (IBD) is a chronic inflammatory disease associated with a dysregulated gastrointestinal and systemic immune system. IBD includes two major disorders: ulcerative colitis (UC) and Crohn's disease (CD). The onset of both CD and UC has a bimodal distribution with peaks occurring either between the 3rd and 4 th or the 6th and 7th decades of life [1]. In addition to a north-south gradient, the prevalence of IBD is population and region dependent with higher rates observed in Northern Europe and North America [2]. In the United States, the prevalence of CD and UC is around 43 and 28 per 100,000 adolescents, and 201 and 238 per 100,000 adults, respectively [2]. Given the chronic and often progressive nature of these diseases, IBD is associated with a significant economic and health care burden.

The treatment of IBD is generally individualized according to several factors including disease phenotype, severity, location, and associated luminal or extraluminal complications. Therapy is generally categorized into two stages: treating an acute flare or induction of remission and maintenance. Significant steps in the treatment of moderate to severe disease were achieved in the last two decades following the introduction of biologic therapy, namely anti-tumor necrosis factor (TNF) inhibitors, resulting in improved clinical outcomes in both $\mathrm{CD}$ and $\mathrm{UC}$ [3]. However, up to one third of IBD patients are resistant

\section{KARGER}

E-Mail karger@karger.com

www.karger.com/iid
Prof. Ala I. Sharara, MD, FACG, AGAF

Division of Gastroenterology, Department of Internal Medicine

American University of Beirut Medical Center

PO Box 11-0236/16-B, Beirut (Lebanon)

E-Mail ala.sharara@ aub.edu.lb 
Fig. 1. The currently approved and available IBD therapies include: four anti-TNF agents, namely infliximab, adalimumab, certolizumab pegol, and golimumab, and two anti-integrin agents, natalizumab and vedolizumab. Ustekinumaband MEDI2070 are human monoclonal IgG antibodies that block the receptor of the p40 subunit of the IL-12/23 complex on leukocytes. Etrolizumab is an anti- $\beta 7$ monoclonal antibody, and tofacitinib is a JAK inhibitor in the JAK/STAT pathway. MAdCAM is a gastrointestinal addressin that binds $\alpha_{4} \beta_{7}$ integrins on leukocytes in the leukocyte recruitment process. $\mathrm{DC}=$ Dendritic cell; $\mathrm{M}=$ microfold cell; $\mathrm{T}_{\mathrm{REG}}$ cell $=$ regulatory $\mathrm{T}$ cells. Reproduced with permission from Danese et al. [83].

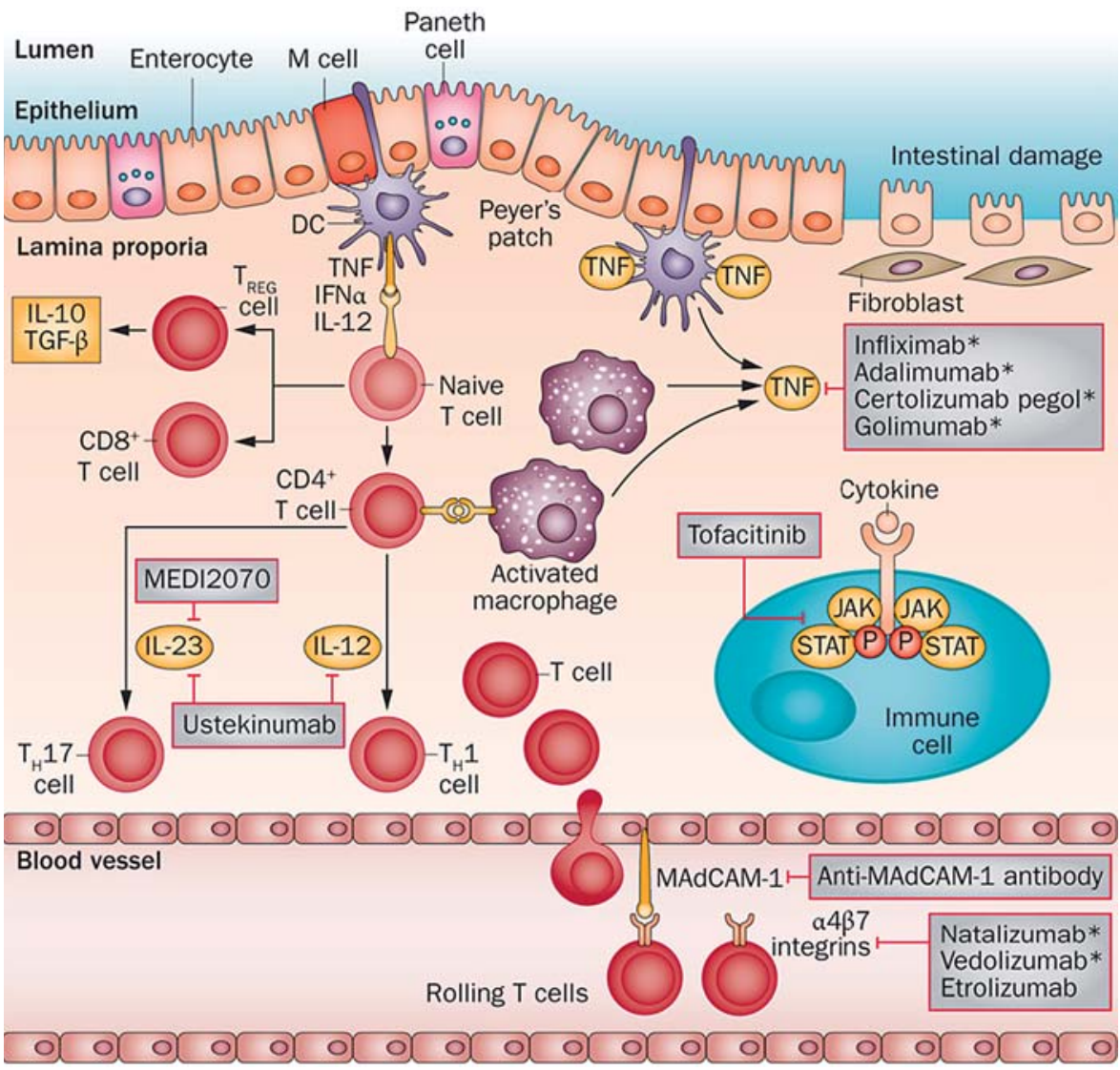

to anti-TNF therapy, and a significant number of patients lose response over time and are left with limited therapeutic options [3]. A deeper understanding of the immunopathology of IBD and an accelerated translational and clinical research program have recently helped identify a number of potential targets for drug development and testing. This review focuses on newer and emerging biological drugs in the treatment of CD and UC.

\section{Interleukin 12/23 Axis}

Cytokines play an important role in any inflammatory response of the human body in the recruitment of and coordination between T-helper-1 $\left(\mathrm{TH}_{1}\right), \mathrm{TH}_{2}$, and cytotoxic lymphocytes. Several inflammatory interleukins, including IL-12/23 and IL-13, are integral to the $\mathrm{TH}_{1}$ or $\mathrm{TH}_{2}$ response and have been shown to be elevated in the disease process in IBD. The roles of IL-12/23 and IL-13 will be discussed in this and the following sections, respectively. IL-12 is an inflammatory cytokine that pro- motes the $\mathrm{TH}_{1}$ pathway in inflammation and has been shown to be part of the response seen in colitis [4]. In addition, the knockout or deactivation of IL-12 has been shown to reduce the intestinal inflammatory response in different mouse models of colitis [5, 6]. IL-12 is made of several subunits. The p40 subunit is shared with another proinflammatory interleukin, IL-23 [7], and the downstream signal of this complex has been shown to activate other T cells and myeloid cells to release TNF- $\alpha$, IL-6, interferon- $\gamma($ IFN- $\gamma)$, and IL-17 in the intestines [8-10], brain [11], and joints [12]. Both IL-12 and IL-23 have been implicated in the pathophysiology of CD (fig. 1) [13-15] and are found at higher levels in the mucosa of CD intestines than in the mucosa of healthy intestines $[13,15]$. Furthermore, a genome-wide association study found a polymorphism in the IL-23 receptor associated with CD [16], while other polymorphisms in the IL-23 receptor gene were found to be protective [17]. In animal models of CD, chronic intestinal inflammation was suppressed when the p40 subunit of IL-12 was neutralized $[18,19]$, and this effect was associated with a decreased 
T-cell response [18]. One clinical trial found that a decrease in IL-12 secretion from mononuclear cells of the colonic lamina propria was associated with clinical improvement in patients receiving anti-IL-12 [20].

Ustekinumab is a human monoclonal IgG antibody that blocks the receptor of the p 40 subunit of the IL-12/23 complex on leukocytes [21-23]. Monoclonal antibodies directed against the p40 subunit of IL-12/23 have also shown efficacy in murine colitis models [21-23]. In humans, phase II clinical trials have shown that ustekinumab is superior to placebo in inducing a response in moderate to severe CD when used both intravenously [20,22] and subcutaneously $[17,22]$. The effect was consistently greater when measured earlier (week $4>6>8$ [20] and week $7>18$ [17]). In the CERTIFI trial [24], response rates were $36.6 \%(\mathrm{p}=0.02), 34.1 \%(\mathrm{p}=0.06)$, and $39.7 \%$ $(\mathrm{p}=0.005)$ with 1,3 , and $6 \mathrm{mg} / \mathrm{kg}$ ustekinumab, respectively, compared to $23.5 \%$ in the placebo arm [24]. Patients with an initial response maintained response with ustekinumab (69.4 vs. $42.5 \%$ placebo; $\mathrm{p}<0.001$ ). Remission rates were not significantly different between ustekinumab and placebo at week 6 , but maintenance of remission was significantly higher in patients with an initial response to ustekinumab ( 41.7 vs. $27.4 \%$ placebo; $\mathrm{p}=$ 0.03 ) [24]. Compared to placebo, there was no significant increase in adverse events $[20,25,26]$ except for injection site reactions noted in one study [17] and a higher number of severe infections in another study [24]. A Cochrane review [26] of both trials of ustekinumab in active $\mathrm{CD}$ [24, 25] found the failure rate to achieve remission with ustekinumab not to be statistically different from placebo [relative risk (RR) 0.94, 95\% CI 0.88-1.01] even when subgrouped by dose. Ustekinumab was, however, associated with a statistically lower rate of failure of response than placebo (RR $0.79,95 \%$ CI $0.71-0.89$ ), with a subgroup analysis showing a significant difference for the 4.5 $\mathrm{mg} / \mathrm{kg}$ dose group [26]. Of note, mucosal healing assessed in 50 patients in the CERTIFI trial was observed in 8 of 41 patients $(19.5 \%)$ receiving ustekinumab compared to 1 of 9 patients (11.1\%) treated with placebo (not significant; $\mathrm{p}=1.00$ ). Studies on IL-12/23 axis-targeting drugs are summarized in table 1.

\section{Interleukin 13}

IL-13 is an inflammatory cytokine that binds to the IL4- $\alpha /$ IL-13- $\alpha 1$ receptor complex. The formed complex phosphorylates and activates signal transducer and activator of transcription 6 (STAT6) that subsequently medi- ates the downstream inflammatory cascade. Of interest, rectal biopsies from patients with UC have demonstrated an increased level of IL-13 mRNA in addition to increased IL-13 secretion compared to normal controls [27, 28]. Anrukinzumab is an anti-IL-13 humanized antibody that binds to IL-13 to prevent its attachment to the IL-4- $\alpha /$ IL13- $\alpha 1$ receptor complex and subsequent activation of the downstream inflammatory response [29]. In a phase IIa multicenter randomized double-blind placebo-controlled trial, 84 patients with active UC were randomized to receive 200, 400, or $600 \mathrm{mg}$ of intravenous anrukinzumab or placebo in 5 doses (weeks $0,2,4,8$, and 12). The primary endpoint was the fold-change in fecal calprotectin at week 14 compared to baseline. No statistical significance in that endpoint was noted at any time point between any of the treatment arms. Improvement in IL13 levels, clinical and endoscopic improvements, and other biological markers were observed in what seemed to be an inverse response fashion with respect to the dose regimen used. The results were also variable and did not tend to significance [30]. There are several limitations to this study including its low power and the high dropout rate $(\sim 27 \%)$ due to adverse events with flares being the most commonly cited adverse events, adding to the possibility of a large selection bias. While preclinical in vivo and in vitro studies hint at IL-13 as a potential treatment target, larger studies including pharmacokinetic studies on anrukinzumab or other anti-IL-13 molecules will be needed to demonstrate efficacy and safety in IBD.

\section{JAK/STAT Pathway}

Janus kinase (JAK) is a signal transducer that acts downstream to cytokines. JAK acts by binding to a cytokine receptor to phosphorylate it. This allows JAK to bind to STAT, after which the complex translocates to the nucleus to initiate transcription of inflammatory genes [31, 32] (fig. 1). Furthermore, IL-12 has been shown to exhibit proinflammatory effects through the $\mathrm{TH}_{1}$ pathway via STAT4 [33]. Polymorphisms in the JAK/STAT pathway have also been associated with IBD [32]. In mouse models of colitis, mice deficient in STAT4 were unable to produce IFN- $\gamma$ in response to IL-12 [5, 34], whereas STAT4 overexpression rendered mice more susceptible to colitis [35]. STAT4 was also found to be overexpressed in T cells from mucosal samples of patients with CD [36]. IL-23, another mediator linked to the function of IL-12, also carries its action through downstream STAT3 [37]. Interestingly, overexpression of STAT3 correlated with a 
Table 1. Summary of the major clinical trials on ustekinumab, vedolizumab, and tofacitinib in CD and UC

\begin{tabular}{|c|c|c|c|}
\hline & Indication & Ustekinumab vs. placebo & Comments \\
\hline \multirow[t]{3}{*}{$\mathrm{CD}$} & Clinical response & $\begin{array}{l}* 36.6 \%(\mathrm{p}=0.02), 34.1 \%(\mathrm{p}=0.06) \text {, and } 39.7 \% \\
(\mathrm{p}=0.005) \text { for } 1,3 \text {, and } 6 \mathrm{mg} / \mathrm{kg} \text { ustekinumab, } \\
\text { respectively, vs. } 23.5 \% \text { placebo at week } 6[24] \\
* * 75 \% \text { ustekinumab vs. } 25 \% \text { placebo }(\mathrm{p}=0.03) \\
\text { at week } 7[20]\end{array}$ & \multirow[t]{2}{*}{$\begin{array}{l}{ }^{*} \text { CERTIFI trial: regimen: } 1,3 \text {, or } 6 \mathrm{mg} \text { ustekinumab per kg body } \\
\text { weight or placebo at week } 0 \text { [24]; trial included patients who had } \\
\text { failed TNF- } \alpha \text { inhibitors only } \\
\text { ** Regimen: } 7 \text { times weekly SC injections }(3 \mathrm{mg} / \mathrm{kg} \text { ) ustekinumab or } \\
\text { placebo }\end{array}$} \\
\hline & Clinical remission & No difference at week $6[20,24]$ & \\
\hline & $\begin{array}{l}\text { Maintenance of } \\
\text { remission }\end{array}$ & $\begin{array}{l}41.7 \% \text { ustekinumab vs. } 27.4 \% \text { placebo } \\
(p=0.03)[24]\end{array}$ & $\begin{array}{l}\text { CERTIFI trial: SC ustekinumab }(90 \mathrm{mg}) \text { or placebo at weeks } 8 \text { and } 16 \text {; } \\
\text { maintenance phase only included responders to ustekinumab at week } \\
6 \text { of induction phase [24] }\end{array}$ \\
\hline
\end{tabular}

\begin{tabular}{lll}
\hline Indication & Tofacitinib vs. placebo & Comments \\
\hline
\end{tabular}

UC Clinical response $\quad 78 \%$ tofacitinib vs. $42 \%$ placebo $(\mathrm{p}<0.001)[42]$ OR: $4.18(1.75-10.02)(\mathrm{p}=0.001)[43]$
Regimen: 15 mg PO twice daily [42, 43]; response rates not significantly different for the $0.5-, 3-$, and $10-\mathrm{mg}$ regimens Endoscopic remission observed with $3 \mathrm{mg}(18 \% ; \mathrm{p}=0.01), 10 \mathrm{mg}$ (30\%; p < 0.001), and $15 \mathrm{mg}(27 \%$; $<$ 0.001) tofacitinib vs. placebo (2\%) [42]

* Regimens: 3, 10, and $15 \mathrm{mg}$ PO twice daily [42]

** Regimen: 15 mg PO twice daily [43] $(\mathrm{p}<0.001), 41 \%$ for $15 \mathrm{mg}$ tofacitinib $(\mathrm{p}<0.001)$ vs. $10 \%$ placebo [42] ** OR: $5.23(2.14-12.75)(\mathrm{p}<0.001)[43]$

\begin{tabular}{|c|c|c|}
\hline & Indication & Vedolizumab vs. placebo \\
\hline \multirow[t]{4}{*}{$\mathrm{CD}$} & Clinical response & $\begin{array}{l}\text { * } 31.4 \% \text { vedolizumab vs. } 25.7 \% \text { placebo at } \\
\text { week } 6(\mathrm{p}=\mathrm{NS})[70] \\
\text { ** } 46.8 \% \text { vedolizumab vs. } 24.8 \% \text { placebo } \\
(\mathrm{p}<0.0001)[71]\end{array}$ \\
\hline & Clinical remission & $\begin{array}{l}* 14.5 \% \text { vedolizumab vs. } 6.8 \% \text { placebo at } \\
\text { week } 6(\mathrm{p}=0.02)[70] \\
\text { ** } 26.6 \% \text { vedolizumab vs. } 12.1 \% \text { placebo at week } \\
10(\mathrm{p}=0.001)[71]\end{array}$ \\
\hline & $\begin{array}{l}\text { Maintenance of } \\
\text { response }\end{array}$ & $\begin{array}{l}* 43.5 \% \text { vedolizumab every } 8 \text { weeks }(\mathrm{p}=0.01) \\
45.5 \% \text { vedolizumab every } 4 \text { weeks } \\
(\mathrm{p}=0.005) \text { vs. } 30.1 \% \text { placebo }[70]\end{array}$ \\
\hline & $\begin{array}{l}\text { Maintenance of } \\
\text { remission }\end{array}$ & $\begin{array}{l}* 39.0 \% \text { vedolizumab every } 8 \text { weeks }(\mathrm{p}<0.001) \\
36.4 \% \text { vedolizumab every } 4 \text { weeks } \\
(\mathrm{p}=0.004) \text { vs. } 21.6 \% \text { placebo }[70]\end{array}$ \\
\hline
\end{tabular}

Comments

* GEMINI-II trial: regimen: IV vedolizumab $300 \mathrm{mg}$ at weeks 0 and 2 [70] ** GEMINI-III trial: regimen: IV vedolizumab $300 \mathrm{mg}$ at weeks 0 , 2, and 6; the response and remission results are significant for patients with prior anti-TNF failure (shown) and the overall study population but not for anti-TNF-naive patients [71]
* Regimen: IV vedolizumab $300 \mathrm{mg}$ every 4 or 8 weeks; includes patients with an initial drop in CDAI $>70$ response to vedolizumab only; the results were also significant for maintenance of glucocorticoid-free remission [70]

\begin{tabular}{|c|c|c|c|}
\hline & Indication & Vedolizumab vs. placebo & Comments \\
\hline \multirow[t]{2}{*}{ UC } & Clinical response & $\begin{array}{l}\text { 47.1\% vedolizumab vs. } 25.5 \% \text { placebo } \\
(\mathrm{p}<0.001)[72]\end{array}$ & $\begin{array}{l}\text { GEMIN-I trial: IV vedolizumab } 300 \mathrm{mg} \text { at weeks } 0 \text { and } 2 \text {; response } \\
\text { was evaluated at week } 6 \text {; vedolizumab was also shown to significantly } \\
\text { induce mucosal healing }(40.9 \%, \mathrm{p}=0.001) \text { as compared to placebo } \\
(24.8 \%) \text { at week } 6\end{array}$ \\
\hline & $\begin{array}{l}\text { Maintenance of } \\
\text { remission }\end{array}$ & $\begin{array}{l}41.8 \% \text { (every } 8 \text { weeks) and } 44.8 \% \text { (every } \\
4 \text { weeks) vs. } 15.9 \% \text { placebo at week } 52 \text { (both } \\
\text { p }<0.001 \text { ) [ } 72]\end{array}$ & Regimen: IV vedolizumab $300 \mathrm{mg}$ every 4 or 8 weeks \\
\hline
\end{tabular}

The number of asterisks indicates which comments in the right column refer to which study in the left column. SC = Subcutaneously; OR = odds ratio; $\mathrm{PO}=$ per os; NS = not significant; IV = intravenously. 
more severe colitis in mice [38], and its expression was shown to be associated with IBD severity scores [39]. On the other hand, when STAT3 was blocked, mice had a lower risk of developing colitis [40]. Hence, the JAK/ STAT pathway constitutes a possible target that theoretically will decrease inflammation if suppressed.

Tofacitinib is an inhibitor of the JAK/STAT pathway that works by inhibiting JAK1 and JAK2 [41] (fig. 1). Compared to placebo, tofacitinib has been shown to have a significantly higher clinical response (78\% tofacitinib vs. $42 \%$ placebo; $\mathrm{p}<0.001$ ) [42] at $15 \mathrm{mg}$ twice daily [42, 43] and higher remission rates [ $3 \mathrm{mg}$ tofacitinib (33\%; $\mathrm{p}=0.01), 10 \mathrm{mg}$ tofacitinib $(48 \% ; \mathrm{p}=0.001)$, and $15 \mathrm{mg}$ tofacitinib $(41 \%$; $<<0.001)$ ] than placebo $(10 \%$; $<<0.001)$ in patients with moderate to severe UC [42]. An endoscopic response evaluated at 8 weeks was significantly higher in the group receiving $15 \mathrm{mg}$ of tofacitinib only than in the placebo group ( 78 vs. $46 \% ; p=0.001$ ). A significant endoscopic remission was observed in patients receiving $3 \mathrm{mg}(18 \% ; \mathrm{p}=0.01), 10 \mathrm{mg}(30 \% ; \mathrm{p}<0 / 001)$, and $15 \mathrm{mg}(27 \%$; $\mathrm{p}<0.001)$ of tofacitinib as compared to placebo (2\%) [42]. This effect, however, was not replicated in patients with CD in whom the drug's effect was not different from placebo [44]. The adverse events were similar in both groups with a dose-dependent increase in low-density cholesterol and high-density cholesterol observed in the treatment group $[42,44]$.

\section{SMAD7 Anti-Sense}

Transforming growth factor- $\beta 1$ (TGF- $\beta 1$ ) is a cytokine with immune-suppressive activity. TGF- $\beta 1$ is actively produced in the normal human gastrointestinal tract to regulate the inflammatory response [45]. Mice with defective TGF- $\beta 1$ are unable to reduce inflammatory cytokines and have been shown to be at increased risk of colitis $[46,47]$. On the other hand, inducing TGF- $\beta 1$ in some models of murine colitis was shown to decrease the severity of colitis $[48,49]$. This response is, however, not seen in all models of IBD, where some models actually increase inflammation in response to TGF- $\beta 1$. The latter effect is explained by the presence of downstream Smad family proteins. The anti-inflammatory effect of TGF- $\beta 1$ is dependent on the subsequent phosphorylation of downstream Smad 2 and 3 that form a heterocomplex with Smad4 to translocate to the nucleus and mediate the antiinflammatory response of TGF- $\beta 1$ (fig. 1) [50]. Smad3 is highly expressed in human colon cells and is phosphorylated to be able to respond to the anti-inflammatory re- sponse of TGF- $\beta 1$ [45]. A diminished response to TGF- $\beta 1$ is seen in mice with deficient Smad3 which are at increased risk of developing chronic inflammation of the colon [51]. Active Smad3 is decreased in both CD and UC [52]. Smad7, on the other hand, inhibits Smad 2 and 3 [50] in addition to promoting the ubiquitin degradation process of TGF- $\beta 1$ [53], which renders TGF- $\beta 1$ a proinflammatory molecule (fig. 2). In mouse models of colitis, there is a marked increase in TGF- $\beta 1$ production in light of reduced active $\mathrm{pSmad} 3$ and high Smad7 activity [54]. Interestingly, Smad7 is overexpressed in CD and UC, and its silencing with an antisense nucleotide or in Smad7 knockdown models was able to reestablish the anti-inflammatory response of TGF- $\beta 1$ [52]. When anti-Smad7 oligonucleotide was administered, a decrease in the severity of colitis was observed in parallel to a restoration of TGF- $\beta 1$ and its anti-inflammatory response [54]. This response was also associated with a decreased level of IL-12 and IFN- $\gamma$, and STAT1 in the JAK/STAT pathway [54]. Smad7 is, therefore, a possible target in the treatment of IBD.

One phase I open-label study on a Smad7 antisense oligonucleotide evaluated 15 patients with $\mathrm{CD}$ resistant to conventional therapy. The patients received mongersen, an oral Smad7 antisense oligonucleotide, once daily for 7 days at doses of 40,80 , or $160 \mathrm{mg}$. The drug was well tolerated and was associated with a reduction in inflammatory cytokine-expressing CCR9-positive T cells [55], a subset of $\mathrm{T}$ cells previously noted to be increased in patients with active CD [56]. A pooled analysis showed a $100 \%$ response rate and clinical remission in 12 of 15 participants [55]. No adverse events were reported. A phase II trial involved 166 patients randomized to 10,40 , or 160 $\mathrm{mg} /$ day of mongersen or placebo for 2 weeks with clinical assessments done at 2, 4, and 12 weeks. Both clinical remission and response rates were significantly higher in patients receiving a 40 or $160 \mathrm{mg} /$ day regimen than in patients receiving placebo at all 3 time points irrespective of disease duration or C-reactive protein (CRP) level [57]. After adjusting for baseline Crohn's Disease Activity In$\operatorname{dex}(\mathrm{CDAI})$ scores in a logistic regression at week 4 , the CDAI score was found to be the only factor affecting the likelihood of clinical remission or response. At week 12, the clinical remission was significantly higher in patients with a CDAI score $<260$ receiving the 40 or $160 \mathrm{mg} /$ day regimen than in the placebo group at all 3 time points (RR at week 12: 78.6, 70.4, and 30.0\%, respectively; $\mathrm{p}<0.001$ ). Similarly, in patients with a baseline CDAI score $>260$, clinical remission was significantly higher in patients receiving the $160 \mathrm{mg} /$ day regimen only than in patients re- 
Fig. 2. SMAD pathway. a TGF- $\beta 1$ binds to the type II receptor to activate the type I receptor. The activated type I receptor phosphorylates Smad2/3 which, once phosphorylated, interact with Smad4 to form the Smad2/3/Smad4 complex. The complex migrates to the nucleus to bind to DNA and activate transcription. b The phosphorylation of Smad3 is prevented through the interaction of Smad7, a TGF- $\beta 1$ type I receptor inhibitor, that binds to and blocks the TGF- $\beta 1$-associated Smad signaling pathway shown in a. Reproduced with permission from Monteleone et al. [84].

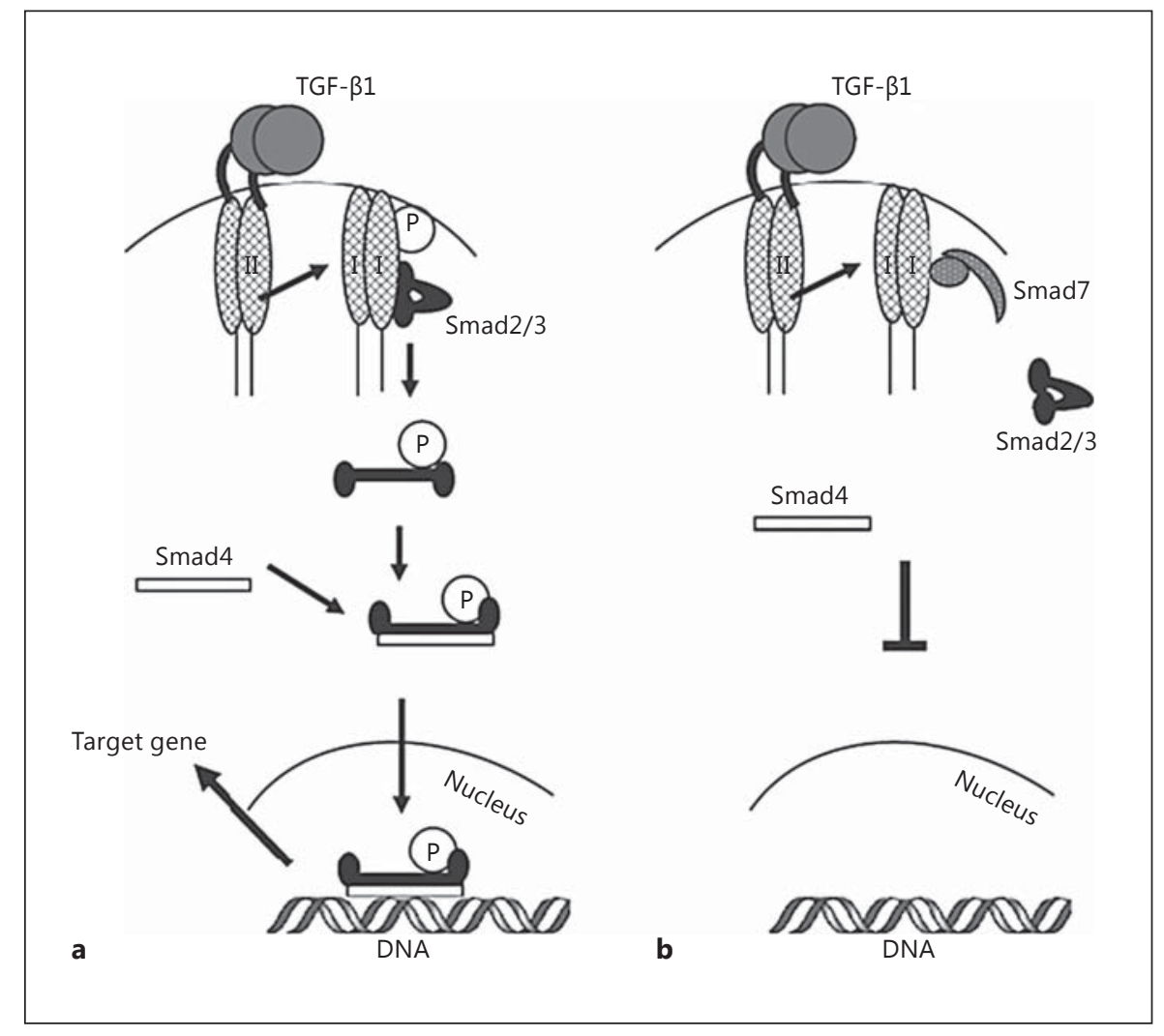

ceiving placebo (RR at week 12: 62.5 vs. $4.5 \%$; $\mathrm{p}<0.001$ ). The response rates had a similar trend at week 12 with an RR of $75.0 \%$ ( $<<0.005), 63.0 \%(\mathrm{p}<0.005)$, and $20.0 \%$, respectively, in patients with a CDAI score $<260$ and a RR of 58.3\% ( $\mathrm{p}<0.05), 87.5 \%$ ( $\mathrm{p}<0.0001$ ), and $22.7 \%$, respectively, in patients with a baseline CDAI score $>260$ [57]. Interestingly, there was a limited effect of mongersen on median CRP levels. Phase III studies are eagerly awaited to confirm these promising results in active CD as well as to address important patient-reported outcomes and endoscopic endpoints.

\section{Cell Adhesion and Leukocyte Recruitment}

As part of the dysregulation seen in the immune response in IBD, leukocytes are recruited at the sites of intestinal inflammation. Leukocyte recruitment occurs in a stepwise manner involving migration and rolling, tightbinding, diapedesis, and migration. These steps utilize adhesion molecules found at the surface of both leukocytes and the vascular endothelium or mucosal epithelium for the recruitment of leukocytes from the circulation to the site of inflammation. An aberrancy in the levels or overall function of these adhesion molecules can either lead to a decreased inflammatory cell recruitment, as observed in hereditary immune deficiency states such as in Chédiak-Higashi syndrome, or a facilitated excessive leukocyte recruitment, as observed in autoimmune diseases [58]. Interestingly, human intestinal mucosal microvascular endothelial cells from mucosa obtained from patients with IBD demonstrated a greater leukocyte-binding capacity than cells from normal mucosa from patients who did not have IBD [59], with some of the mediators, including intercellular adhesion molecule-1, integrins, vascular cell adhesion molecule-1, and mucosal addressin cell adhesion molecule-1 (MAdCAM-1), already associated with the pathogenicity in IBD (fig. 1) [60]. This has led to the idea of developing potential drugs that target adhesion molecules in an attempt to block leukocyte recruitment and subsequently reduce inflammation [6163]. Targeting adhesion molecules in in vitro and in vivo models of leukocyte adhesion reduced acute and chronic intestinal inflammation [58]. Hence, disrupting the function of these molecules provides a novel approach to the treatment of IBD. 


\section{Anti- $\alpha$-Integrin Antibodies}

Natalizumab

Natalizumab is a humanized monoclonal antibody against a4 integrin. a4 integrin is a leukocyte membrane glycoprotein that binds to fibronectin and other endothelial glycoproteins to mediate leukocyte migration and trafficking. Natalizumab targets subunits $\alpha_{4} \beta_{7}$ and $\alpha_{4} \beta_{1}$ of the $\alpha$ integrin that are specific to the gut and the central nervous system, respectively $[64,65]$. In moderate to severe $C D$, anti- $\alpha$-integrin antibodies are used in the treatment of patients who do not respond to corticosteroids, immunomodulators, or anti-TNF- $\alpha$ therapy [66, 67]. The Efficacy of Natalizumab in CD Response and Remission (ENCORE) and Efficacy of Natalizumab as Active Crohn's Therapy (ENACT) trials were the two major clinical trials looking at natalizumab in CD patients. In the ENCORE trial, natalizumab was shown to result in a significantly higher induction of response ( $60 \%$ natalizumab vs. $44 \%$ placebo; $\mathrm{p}<$ 0.001 ) and remission (38\% natalizumab vs. $25 \%$ placebo at week $12 ; \mathrm{p}=0.001)$ rates than placebo when given in a 4-week regimen [66]. The ENACT-1 trial followed with almost double the number of patients, and the treatment allocation was stratified according to disease activity and use of corticosteroids. There was no difference in clinical response ( $56 \%$ natalizumab vs. $49 \%$ placebo; $\mathrm{p}=0.05)$ or clinical remission $(37 \%$ natalizumab vs. $30 \%$ placebo; $p=0.12$ ) [67]. In the maintenance phase of the ENACT-2 trial, patients with an initial response to natalizumab from the ENACT-1 trial were further randomized to receive natalizumab or placebo. A significantly higher maintenance of both response ( $61 \%$ natalizumab vs. $28 \%$ placebo; $p<0.001)$ and remission ( $44 \%$ natalizumab vs. $26 \%$ placebo; $p=0.003$ ) rates was observed at 36 weeks [67]. The results were significant in patients with elevated CRP and in patients with prior anti-TNF treatment but not in those naive to anti-TNF treatment [67].

Only one clinical trial evaluated the effect of natalizumab in UC. Gordon et al. [68] looked at the effect of a single $3 \mathrm{mg} / \mathrm{kg}$ natalizumab infusion in 10 patients with UC in an open-label trial. Natalizumab led to a significant decrease in the median Powell-Tuck score at 2 and 4 weeks as compared to baseline with only 1 patient remaining in remission at 12 weeks [68].

Natalizumab is currently not used in the treatment of IBD given its associated risk of progressive multifocal leukoencephalopathy (PML), a rare but serious opportunistic infection caused by the JC virus. PML has been reported in IBD patients receiving natalizumab [67], but larger studies on incidence come from patients with multiple sclerosis with an estimated incidence of 11.1 cases per 1,000 patients (95\% CI 8.3-14.5) [69].

\section{Vedolizumab}

Vedolizumab is another humanized monoclonal antibody that blocks a integrin. Unlike natalizumab, vedolizumab blocks only the $\alpha_{4} \beta_{7}$ receptor and is thought to be selective to the gastrointestinal tract. This helps decrease the risk of PML posed by natalizumab. The GEMINI-II trial in CD patients demonstrated that vedolizumab (300 mg intravenously at weeks 0,2 , and 6) resulted in a better remission ( $14.5 \%$ vedolizumab vs. $6.8 \%$ placebo; $\mathrm{p}=0.02$ ) but not response rate ( $31.4 \%$ vedolizumab vs. $25.7 \%$ placebo; $\mathrm{p}=0.23)$ at 6 weeks than placebo [70] unless the patients were nonresponders to anti-TNF- $\alpha$ treatment as in the GEMINI-III trial [71]. In the maintenance phase of the GEMINI-II trial, however, CD patients had significantly higher response rates [ $43.5 \%$ vedolizumab every 8 weeks $(\mathrm{p}<0.01)$ and $45.5 \%$ vedolizumab every 4 weeks $(\mathrm{p}=0.005)$ vs. $30.1 \%$ placebo $]$ and remission rates $[39.0 \%$ vedolizumab every 8 weeks $(\mathrm{p}<0.001)$ and $36.4 \%$ vedolizumab every 4 weeks $(\mathrm{p}=0.004)$ vs. $21.6 \%$ placebo] at 52 weeks if an initial clinical response to vedolizumab was noted at 6 weeks of the study [70]. In the GEMINI-III trial, patients with previous TNF antagonism failure were randomized to receive intravenous vedolizumab or placebo at weeks 0,2 , and 6 . At week $6,15.2 \%$ of patients receiving vedolizumab were in clinical remission as compared to $12.1 \%$ of patients receiving placebo $(\mathrm{p}=0.43)$. At week 10 , the remission rate was higher and tended to significance, namely $26.6 \%$ in patients receiving vedolizumab as compared to $12.1 \%$ in patients receiving placebo (nominal $\mathrm{p}=0.001$ ), and the response rate was $39.2 \%$ as compared to $22.3 \%$ in the placebo arm (nominal $\mathrm{p}=$ $0.001)[71]$.

In patients with UC, the GEMINI-I trial demonstrated that vedolizumab was superior to placebo in inducing clinical remission ( $41.8 \%$ vedolizumab vs. $15.9 \%$ placebo; $\mathrm{p}<0.001)$ [72] and response (47.1\% vedolizumab vs. $25.5 \%$ placebo; $\mathrm{p}<0.001)$. Vedolizumab was also shown to significantly induce mucosal healing compared to placebo ( 40.9 vs. $24.8 \% ; \mathrm{p}=0.001$ ) at week 6 . In the maintenance phase of the GEMINI-I trial, vedolizumab was found to maintain clinical remission $[41.8 \%(300 \mathrm{mg} \mathrm{ev}-$ ery 8 weeks) and $44.8 \%$ (300 mg every 4 weeks) vs. $15.9 \%$ placebo; both $\mathrm{p}<0.001$ ] and response at 52 weeks in patients with an initial response to vedolizumab [72]. The details of the studies are summarized in table 1. Vedolizumab was recently approved for both CD and UC. 


\section{Etrolizumab}

Etrolizumab, an anti- $\beta 7$ monoclonal antibody, is a dual-action anti-integrin antibody designed to selectively control gut inflammation in IBD. Etrolizumab binds both the $\alpha_{4} \beta_{7}$ integrin, preventing leukocytes from binding to MAdCAM-1, and the $\alpha E \beta_{7}$ integrin subunit, preventing leukocytes from binding to E-cadherin, and potentially inhibiting the retention of leukocytes in the gut mucosa. Similar to vedolizumab, etrolizumab blocks the $\alpha_{4} \beta_{7}$ receptor only and is thought to be selective to the gastrointestinal tract and more specifically to mucosal tissue with a minimal effect on nonmucosal sites [60]. In a phase II trial of patients with moderate to severe UC not responding to conventional treatment, etrolizumab was given subcutaneously at $100 \mathrm{mg}$ at weeks 0,4 , and 8 , with placebo at week 2; or a 420-mg loading dose was given at week 0 followed by $300 \mathrm{mg}$ at weeks 2,4 , and 8 , or matching placebo. Both treatment groups had a significantly higher remission rate compared to placebo at week 10 [21\% in the $100-\mathrm{mg}$ group $(\mathrm{p}=0.0040)$ and $10 \%$ in the 300 -mg plus loading-dose group $(\mathrm{p}=0.048)$ vs. $0 \%$ in the placebo group]. No difference in the frequency of serious adverse effects was reported [73]. Of interest, the expression of $\alpha E$ integrin on real-time quantitative PCR or immunohistochemistry was associated with a significant response to etrolizumab.

\section{Cell Adhesion Molecules}

Cell adhesion molecules are the mucosal counterpart of the $\alpha$ integrins found on leukocytes. MAdCAM- 1 is a gastrointestinal addressin that binds $\alpha_{4} \beta_{7}$ integrins on leukocytes in the recruitment process mentioned above. PF-00547659 is a human monoclonal antibody that neutralizes MAdCAM-1 glycoproteins. In vitro, this effect has been shown to block the adhesion of MAdCAM-1 to a integrin-bearing leukocytes [74]. Preliminary results of a phase II trial in patients with UC showed significant clinical and endoscopic response in addition to remission rates compared to placebo. Results were most significant when the drug was taken as $22.5 \mathrm{mg}$ every 4 weeks for 3 doses and in anti-TNF- $\alpha$-naive patients [75].

\section{Sphingosine Kinase 1}

Complex sphingolipids are integral components of cell membranes, including the intestinal border epithelium, and function as a protective barrier in addition to regulating several intracellular processes. Sphingosine kinase 1 (SK1) is a lipid kinase that generates sphingosine-1-phosphate (S1P) and ceramide-1-phospate (C1P) from the precursor sphingolipids, sphingosine and ceramide, respectively. SK1 and S1P are shown to regulate several inflammatory cascades and have been associated with several inflammatory diseases. Similar to the MAdCAM inhibitors discussed above, targeting the S1P pathway impedes lymphocyte trafficking and has been shown to be therapeutic in autoimmune disorders, especially in multiple sclerosis [76]. Preclinical studies in animal models of colitis have revealed that targeting the sphingolipid pathways is a potential therapeutic pathway in IBD $[77,78]$. In rat models of intestinal inflammation, proinflammatory cytokines such as TNF- $\alpha$ and IL- $\beta$ have been shown to activate SK1 both in vivo and in vitro [79]. Activation of SK1 leads to the production of S1P that acts on S1P receptor 1. The latter will upregulate STAT3 and NF- $\kappa \mathrm{B}$. NF- $\kappa \mathrm{B}$ subsequently acts as one of the main activators of IL-6, a proinflammatory cytokine [80]. STAT3 was also shown to inhibit carcinogenic properties. Nonetheless, S1P and C1P levels are elevated in mouse models of colitis [77] and increased in parallel to inflammation in a rat model of intestinal inflammation [78]. Of interest, higher levels of ceramide and sphingomyelin were found in the ileum of patients with CD. In the recent TOUCHSTONE study, high (1 mg) and low (0.5 mg) doses of ozanimod (RPC1063), an S1P receptor modulator, were compared in a 1:1:1 ratio to placebo in 197 patients with moderate to severe UC. Ozanimod at high doses was shown to significantly induce response, remission, and mucosal healing in patients with moderate to severe UC, proving that targeting mediators downstream of the sphingolipid inflammation cascade is a potential novel target in the treatment of IBD. In the maintenance phase of the TOUCHSTONE study, 103 patients who had clinical response at week 8 continued to receive the same regimen of ozanimod for another 24 weeks for a total of 32 weeks. Patients receiving the $1-\mathrm{mg}$ dose either achieved or maintained remission $(21 \%$ ozanimod vs. $6 \%$ placebo; $\mathrm{p}=0.011)$, clinical response ( $51 \%$ ozanimod vs. $20 \%$ placebo; $\mathrm{p}=0.0002$ ), and mucosal healing ( $32.8 \%$ ozanimod vs. $12.3 \%$ placebo; $\mathrm{p}=0.0046)[81]$.

\section{Conclusion}

IBD is a heterogeneous disease with a complex and multifactorial pathobiology and immunology. The introduction of biological therapy, namely anti-TNF inhibi- 
tors, resulted in improved clinical outcomes in both CD and UC, but important unmet needs remain. Novel targeted immunotherapies are under active investigation offering promising early results, but their use in clinical practice will require validation in large randomized controlled trials with clear patient-reported outcomes and objective measures of disease activity [82]. The widely variable rates of response (or lack of response) seen with these newer agents underscore the complex pathophysi- ology and heterogeneity of IBD and highlight the future need for precision medicine using a personalized approach based on molecular, immunologic, and genetic research in IBD.

\section{Disclosure Statement}

The authors have no conflicts of interest to declare.

\section{References}

$\checkmark 1$ Ekbom A, Helmick C, Zack M, Adami HO: $>11$ Cua DJ, Sherlock J, Chen Y, et al: InterleuThe epidemiology of inflammatory bowel disease: a large, population-based study in Sweden. Gastroenterology 1991;100:350-358.

2 Kappelman MD, Rifas-Shiman SL, Kleinman $\mathrm{K}$, et al: The prevalence and geographic distribution of Crohn's disease and ulcerative colitis in the United States. Clin Gastroenterol Hepatol 2007;5:1424-1429.

3 Hazlewood GS, Rezaie A, Borman M, et al: Comparative effectiveness of immunosuppressants and biologics for inducing and maintaining remission in Crohn's disease: a network meta-analysis. Gastroenterology 2015;148:344-354.e5; quiz e14-e15.

4 Bouma G, Strober W: The immunological and genetic basis of inflammatory bowel disease. Nat Rev Immunol 2003;3:521-533.

5 Simpson SJ, Shah S, Comiskey M, et al: T cellmediated pathology in two models of experimental colitis depends predominantly on the interleukin 12/signal transducer and activator of transcription (STAT)-4 pathway, but is not conditional on interferon $\gamma$ expression by $\mathrm{T}$ cells. J Exp Med 1998;187:1225-1234.

6 Neurath MF, Fuss I, Kelsall BL, Stuber E, Strober W: Antibodies to interleukin 12 abrogate established experimental colitis in mice. J Exp Med 1995;182:1281-1290.

7 Oppmann B, Lesley R, Blom B, et al: Novel p19 protein engages IL-12p40 to form a cytokine, IL-23, with biological activities similar as well as distinct from IL-12. Immunity 2000; 13:715-725.

$\checkmark 8$ Hue S, Ahern P, Buonocore S, et al: Interleukin-23 drives innate and $\mathrm{T}$ cell-mediated intestinal inflammation. J Exp Med 2006;203: 2473-2483.

-9 Uhlig HH, McKenzie BS, Hue S, et al: Differential activity of IL-12 and IL-23 in mucosal and systemic innate immune pathology. Immunity 2006;25:309-318.

10 Yen D, Cheung J, Scheerens H, et al: IL-23 is essential for T cell-mediated colitis and promotes inflammation via IL-17 and IL-6. J Clin Invest 2006;116:1310-1316. kin-23 rather than interleukin-12 is the critical cytokine for autoimmune inflammation of the brain. Nature 2003;421:744-748.

12 Murphy CA, Langrish CL, Chen Y, et al: Divergent pro- and antiinflammatory roles for IL-23 and IL-12 in joint autoimmune inflammation. J Exp Med 2003;198:1951-1957.

13 Duerr RH, Taylor KD, Brant SR, et al: A genome-wide association study identifies IL23R as an inflammatory bowel disease gene. Science 2006;314:1461-1463.

14 Iwakura $\mathrm{Y}$, Ishigame H: The IL-23/IL-17 axis in inflammation. J Clin Invest 2006;116: 1218-1222.

15 Berrebi D, Besnard M, Fromont-Hankard G, et al: Interleukin-12 expression is focally enhanced in the gastric mucosa of pediatric patients with Crohn's disease. Am J Pathol 1998; 152:667-672.

16 Wang K, Zhang H, Kugathasan S, et al: Diverse genome-wide association studies associate the IL12/IL23 pathway with Crohn disease. Am J Hum Genet 2009;84:399-405.

17 Baumgart DC, Sandborn WJ: Crohn's disease. Lancet 2012;380:1590-1605.

18 Rutgeerts P, Feagan BG, Lichtenstein GR, et al: Comparison of scheduled and episodic treatment strategies of infliximab in Crohn's disease. Gastroenterology 2004;126:402-413.

19 Schreiber S, Khaliq-Kareemi M, Lawrance IC, et al: Maintenance therapy with certolizumab pegol for Crohn's disease. N Engl J Med 2007; 357:239-250.

20 Mannon PJ, Fuss IJ, Mayer L, et al: Anti-interleukin-12 antibody for active Crohn's disease. N Engl J Med 2004;351:2069-2079.

21 Becker C, Dornhoff H, Neufert C, et al: Cutting edge: IL-23 cross-regulates IL-12 production in T cell-dependent experimental colitis. J Immunol 2006;177:2760-2764.

22 Yen D, Cheung J, Scheerens H, et al: IL-23 is essential for T cell-mediated colitis and promotes inflammation via IL-17 and IL-6. J Clin Invest 2006;116:1310-1316.

23 Mannon PJ, Fuss IJ, Mayer L, et al: Anti-interleukin-12 antibody for active Crohn's disease. N Engl J Med 2004;351:2069-2079.
24 Sandborn WJ, Gasink C, Gao LL, et al: Ustekinumab induction and maintenance therapy in refractory Crohn's disease. N Engl J Med 2012;367:1519-1528.

25 Sandborn WJ, Feagan BG, Fedorak RN, et al: A randomized trial of ustekinumab, a human interleukin-12/23 monoclonal antibody, in patients with moderate-to-severe Crohn's disease. Gastroenterology 2008;135:11301141.

26 Khanna R, Preiss JC, MacDonald JK, Timmer A: Anti-IL-12/23p40 antibodies for induction of remission in Crohn's disease. Cochrane Database Syst Rev 2015;5:CD007572.

27 Inoue S, Matsumoto T, Iida M, et al: Characterization of cytokine expression in the rectal mucosa of ulcerative colitis: correlation with disease activity. Am J Gastroenterol 1999;94: 2441-2446.

28 Fuss IJ, Heller F, Boirivant M, et al: Nonclassical CD1d-restricted NK T cells that produce IL-13 characterize an atypical Th2 response in ulcerative colitis. J Clin Invest 2004;113: 1490-1497.

29 Kasaian MT, Tan XY, Jin M, et al: Interleukin-13 neutralization by two distinct receptor blocking mechanisms reduces immunoglobulin $\mathrm{E}$ responses and lung inflammation in cynomolgus monkeys. J Pharmacol Exp Ther 2008;325:882-892.

30 Reinisch W, Panes J, Khurana S, et al: Anrukinzumab, an anti-interleukin 13 monoclonal antibody, in active UC: efficacy and safety from a phase IIa randomised multicentre study. Gut 2015;64:894-900.

31 O'Shea JJ, Plenge R: JAK and STAT signaling molecules in immunoregulation and immune-mediated disease. Immunity 2012;36: 542-550.

- 32 Ferguson LR, Han DY, Fraser AG, et al: Genetic factors in chronic inflammation: single nucleotide polymorphisms in the STAT-JAK pathway, susceptibility to DNA damage and Crohn's disease in a New Zealand population. Mutat Res 2010;690:108-115. 
33 Trinchieri G: Interleukin-12 and the regulation of innate resistance and adaptive immunity. Nat Rev Immunol 2003;3:133-146.

- 34 Bacon CM, Petricoin EF 3rd, Ortaldo JR, et al: Interleukin 12 induces tyrosine phosphorylation and activation of STAT4 in human lymphocytes. Proc Natl Acad Sci USA 1995;92: 7307-7311.

35 Wirtz S, Finotto S, Kanzler S, et al: Cutting edge: chronic intestinal inflammation in STAT-4 transgenic mice: characterization of disease and adoptive transfer by TNF- plus IFN- $\gamma$-producing CD4+ T cells that respond to bacterial antigens. J Immunol 1999;162: 1884-1888.

- 36 Parrello T, Monteleone G, Cucchiara S, et al: Up-regulation of the IL-12 receptor $\beta 2$ chain in Crohn's disease. J Immunol 2000;165: 7234-7239.

37 McKenzie BS, Kastelein RA, Cua DJ: Understanding the IL-23-IL-17 immune pathway. Trends Immunol 2006;27:17-23.

- 38 Suzuki A, Hanada T, Mitsuyama K, et al: CIS3/SOCS3/SSI3 plays a negative regulatory role in STAT3 activation and intestinal inflammation. J Exp Med 2001;193:471-481.

-39 Musso A, Dentelli P, Carlino A, et al: Signal transducers and activators of transcription 3 signaling pathway: an essential mediator of inflammatory bowel disease and other forms of intestinal inflammation. Inflamm Bowel Dis 2005;11:91-98.

-40 Atreya R, Mudter J, Finotto S, et al: Blockade of interleukin 6 trans signaling suppresses Tcell resistance against apoptosis in chronic intestinal inflammation: evidence in Crohn disease and experimental colitis in vivo. Nat Med 2000;6:583-588.

-41 Borie DC, O’Shea JJ, Changelian PS: JAK3 inhibition, a viable new modality of immunosuppression for solid organ transplants. Trends Mol Med 2004;10:532-541.

42 Sandborn WJ, Ghosh S, Panes J, et al: Tofacitinib, an oral Janus kinase inhibitor, in active ulcerative colitis. N Engl J Med 2012;367:616624.

43 Panes J, Su C, Bushmakin AG, Cappelleri JC, Mamolo C, Healey P: Randomized trial of tofacitinib in active ulcerative colitis: analysis of efficacy based on patient-reported outcomes. BMC Gastroenterol 2015;15:14.

-44 Sandborn WJ, Ghosh S, Panes J, et al: A phase 2 study of tofacitinib, an oral Janus kinase inhibitor, in patients with Crohn's disease. Clin Gastroenterol Hepatol 2014;12:1485-1493. e2.

45 Di Sabatino A, Pickard KM, Rampton D, et al: Blockade of transforming growth factor $\beta$ upregulates T-box transcription factor T-bet, and increases Thelper cell type 1 cytokine and matrix metalloproteinase- 3 production in the human gut mucosa. Gut 2008;57:605-612.

-46 Gorelik L, Flavell RA: Transforming growth factor- $\beta$ in T-cell biology. Nat Rev Immunol 2002;2:46-53.
47 Kulkarni AB, Karlsson S: Transforming growth factor- $\beta 1$ knockout mice. A mutation in one cytokine gene causes a dramatic inflammatory disease. Am J Pathol 1993;143: 3-9.

48 Monteleone G, Parrello T, Luzza F, Pallone F: Response of human intestinal lamina propria T lymphocytes to interleukin 12: additive effects of interleukin 15 and 7. Gut 1998;43: 620-628.

49 Monteleone G, Biancone L, Marasco R, et al: Interleukin 12 is expressed and actively released by Crohn's disease intestinal lamina propria mononuclear cells. Gastroenterology 1997;112:1169-1178.

50 Trinchieri G: Interleukin-12: a cytokine produced by antigen-presenting cells with immunoregulatory functions in the generation of T-helper cells type 1 and cytotoxic lymphocytes. Blood 1994;84:4008-4027.

51 Monteleone G, Parrello T, Monteleone I, Tammaro S, Luzza F, Pallone F: Interferon- $\gamma$ (IFN- $\gamma$ ) and prostaglandin E2 (PGE2) regulate differently IL-12 production in human intestinal lamina propria mononuclear cells (LPMC). Clin Exp Immunol 1999;117:469475.

52 Monteleone G, Kumberova A, Croft NM, McKenzie C, Steer HW, MacDonald TT: Blocking Smad7 restores TGF- $\beta 1$ signaling in chronic inflammatory bowel disease. J Clin Invest 2001;108:601-609.

53 Fuss IJ, Marth T, Neurath MF, Pearlstein GR, Jain A, Strober W: Anti-interleukin 12 treatment regulates apoptosis of Th1 T cells in experimental colitis in mice. Gastroenterology 1999;117:1078-1088.

54 Boirivant M, Pallone F, Di Giacinto C, et al: Inhibition of Smad7 with a specific antisense oligonucleotide facilitates TGF- $\beta 1$-mediated suppression of colitis. Gastroenterology 2006; 131:1786-1798.

55 Monteleone G, Fantini MC, Onali S, et al: Phase I clinical trial of Smad7 knockdown using antisense oligonucleotide in patients with active Crohn's disease. Mol Ther 2012;20: 870-876.

56 Geremia A, Arancibia-Carcamo CV, Fleming MP, et al: IL-23-responsive innate lymphoid cells are increased in inflammatory bowel disease. J Exp Med 2011;208:1127-1133.

57 Monteleone G, Di Sabatino A, Ardizzone S, et al: Impact of patient characteristics on the clinical efficacy of mongersen (GED-0301), an oral Smad7 antisense oligonucleotide, in active Crohn's disease. Aliment Pharmacol Ther 2016;43:717-724.

58 Panes J, Perry M, Granger DN: Leukocyteendothelial cell adhesion: avenues for therapeutic intervention. Br J Pharmacol 1999;126: 537-550.

59 Binion DG, West GA, Ina K, Ziats NP, Emancipator SN, Fiocchi C: Enhanced leukocyte binding by intestinal microvascular endothelial cells in inflammatory bowel disease. Gastroenterology 1997;112:1895-1907.
60 Rivera-Nieves J: Strategies that target leukocyte traffic in inflammatory bowel diseases: recent developments. Curr Opin Gastroenterol 2015;31:441-448.

61 Nakamura K, Honda K, Mizutani T, Akiho H, Harada N: Novel strategies for the treatment of inflammatory bowel disease: selective inhibition of cytokines and adhesion molecules. World J Gastroenterol 2006;12:4628-4635.

62 Danese S: New therapies for inflammatory bowel disease: from the bench to the bedside. Gut 2012;61:918-932.

63 Sans M, Panes J, Ardite E, et al: VCAM-1 and ICAM-1 mediate leukocyte-endothelial cell adhesion in rat experimental colitis. Gastroenterology 1999;116:874-883.

64 Yednock TA, Cannon C, Fritz LC, SanchezMadrid F, Steinman L, Karin N: Prevention of experimental autoimmune encephalomyelitis by antibodies against $\alpha_{4} \beta_{1}$ integrin. Nature 1992;356:63-66.

65 Polman CH, O’Connor PW, Havrdova E, et al: A randomized, placebo-controlled trial of natalizumab for relapsing multiple sclerosis. N Engl J Med 2006;354:899-910.

66 Targan SR, Feagan BG, Fedorak RN, et al: Natalizumab for the treatment of active Crohn's disease: results of the ENCORE trial. Gastroenterology 2007;132:1672-1683.

67 Sandborn WJ, Colombel JF, Enns R, et al: Natalizumab induction and maintenance therapy for Crohn's disease. N Engl J Med 2005; 353:1912-1925.

68 Gordon FH, Hamilton MI, Donoghue S, et al: A pilot study of treatment of active ulcerative colitis with natalizumab, a humanized monoclonal antibody to $\alpha 4$ integrin. Aliment Pharmacol Ther 2002;16:699-705.

69 Bloomgren G, Richman S, Hotermans C, et al: Risk of natalizumab-associated progressive multifocal leukoencephalopathy. N Engl J Med 2012;366:1870-1880.

70 Sandborn WJ, Feagan BG, Rutgeerts P, et al: Vedolizumab as induction and maintenance therapy for Crohn's disease. N Engl J Med 2013;369:711-721.

71 Sands BE, Feagan BG, Rutgeerts P, et al: Effects of vedolizumab induction therapy for patients with Crohn's disease in whom tumor necrosis factor antagonist treatment failed. Gastroenterology 2014;147:618-627.e3.

72 Feagan BG, Rutgeerts P, Sands BE, et al: Vedolizumab as induction and maintenance therapy for ulcerative colitis. N Engl J Med 2013;369:699-710.

73 Vermeire S, O’Byrne S, Keir M, et al: Etrolizumab as induction therapy for ulcerative colitis: a randomised, controlled, phase 2 trial. Lancet 2014;384:309-318.

74 Pullen N, Molloy E, Carter D, et al: Pharmacological characterization of PF-00547659, an anti-human MAdCAM monoclonal antibody. Br J Pharmacol 2009;157:281-293. 
75 Vermeire S, Sandborn W, Danese S, et al: OP021 TURANDOT: a randomized, multicenter double-blind, placebo-controlled study of the safety and efficacy of anti-MAdCAM antibody PF-00547659 (PF) in patients with moderate to severe ulcerative colitis (UC). J Crohns Colitis 2015;9:S13.

76 Kappos L, Antel J, Comi G, et al: Oral fingolimod (FTY720) for relapsing multiple sclerosis. N Engl J Med 2006;355:1124-1140.

77 Fischbeck A, Leucht K, Frey-Wagner I, et al: Sphingomyelin induces cathepsin D-mediated apoptosis in intestinal epithelial cells and increases inflammation in DSS colitis. Gut 2011;60:55-65.
78 Braun A, Treede I, Gotthardt D, et al: Alterations of phospholipid concentration and species composition of the intestinal mucus barrier in ulcerative colitis: a clue to pathogenesis. Inflamm Bowel Dis 2009;15:1705-1720.

79 Snider AJ, Ali WH, Sticca JA, et al: Distinct roles for hematopoietic and extra-hematopoietic sphingosine kinase-1 in inflammatory bowel disease. PLoS One 2014;9:e113998.

80 Theiss AL: Sphingosine-1-phosphate: driver of NFKB and STAT3 persistent activation in chronic intestinal inflammation and colitisassociated cancer. JAKSTAT 2013;2:e24150.

81 Sandborn W, Feagan BG, Wolf DC, et al: 445 The TOUCHSTONE study: a randomized, double-blind, placebo-controlled induction trial of an oral S1P receptor modulator (RPC1063) in moderate to severe ulcerative colitis. Gastroenterology 2015;148:S-93.
82 Peyrin-Biroulet L, Sandborn W, Sands BE, et al: Selecting Therapeutic Targets in Inflammatory Bowel Disease (STRIDE): determining therapeutic goals for treat-to-target. Am J Gastroenterol 2015;110:1324-1338.

83 Danese S, Vuitton L, Peyrin-Biroulet L: Biologic agents for IBD: practical insights. Nat Rev Gastroenterol Hepatol 2015;12:537-545.

84 Monteleone G, Boirivant M, Pallone F, MacDonald TT: TGF- $\beta 1$ and Smad7 in the regulation of IBD. Mucosal Immunol 2008; 1 (suppl 1):S50-S53 